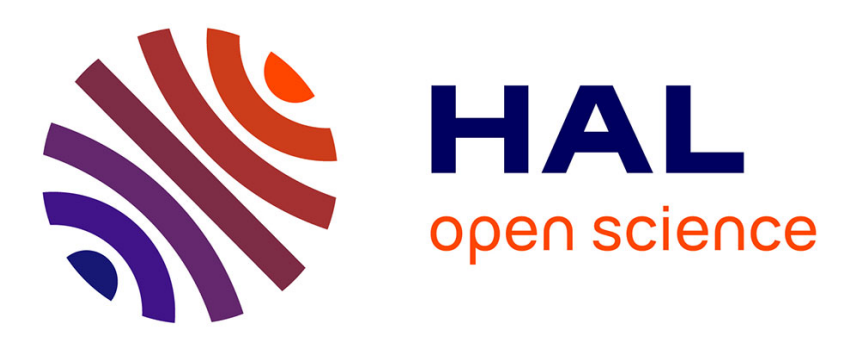

\title{
ELLIPSOMETRIC FORMULAS FOR AN INDEX PROFILE OF SMALL AMPLITUDE BUT ARBITRARY SHAPE
}

J. Charmet, P.-G. de Gennes

\section{- To cite this version:}

J. Charmet, P.-G. de Gennes. ELLIPSOMETRIC FORMULAS FOR AN INDEX PROFILE OF SMALL AMPLITUDE BUT ARBITRARY SHAPE. Journal de Physique Colloques, 1983, 44 (C10), pp.C10-27-C10-29. 10.1051/jphyscol:19831004 . jpa-00223453

HAL Id: jpa-00223453

https://hal.science/jpa-00223453

Submitted on 1 Jan 1983

HAL is a multi-disciplinary open access archive for the deposit and dissemination of scientific research documents, whether they are published or not. The documents may come from teaching and research institutions in France or abroad, or from public or private research centers.
L'archive ouverte pluridisciplinaire HAL, est destinée au dépôt et à la diffusion de documents scientifiques de niveau recherche, publiés ou non, émanant des établissements d'enseignement et de recherche français ou étrangers, des laboratoires publics ou privés. 


\title{
ELLIPSOMETRIC FORMULAS FOR AN INDEX PROFILE OF SMALL AMPLITUDE BUT
}

\section{ARBI TRARY SHAPE}

\author{
J.C. Charmet and P.G. de Gennes \\ Ecole Supémieure de Physique et de Chimie Industrielles de la ville de Paris, \\ (E.S.P.C.I.), 10, me Vauquelin, 75231 Paris Cedex 05, France
}

Rẽsumé - Le plus souvent les réflectances de couches non homogènes sont calcuTées par résolution numérique des équations de Maxwell. Pour certains problèmes physiques cette procédure ne permet pas bien de résoudre le problème inverse, c'est-à-dire de déterminer le profil d'indice $n(z)$ à partir des mesures ellipsométriques ( $\psi$ et $\Delta$ ). Ici nous calculons les rëflectances explicitement pour $n$ 'importe quelle forme de $n(z)$ par une approximation de Eorn, valable au premier ordre en $n(z)-n_{0}$ (où $n_{0}$ est 1 indice du milieu d'incidence). Par contre, l'effet de la paroi réfléchissante (en $z=0$ ) est incorporé dans le problème non perturbé. $\psi$ et $\Delta$ sont ainsi exp̣rimés en fonction de la transformée de Fourier complexe $\Gamma(2 q)=\Gamma^{\prime}+i \Gamma^{\prime \prime}$ du profil (où q est la composante normale du vecteur d'onde incident). Pour des couches énaisses (e $\gg \lambda / 4 \pi$ ) ceci doit permettre une reconstruction complète du profil. Pour des couches minces $(e<\lambda / 4 \pi)$ on détermine seulement les premiers moments du profil d'indice. Pour illustrer ces techniques, nous discutons deux exemples qui font intervenir un profil d'indice lentement décroissant : (i) effets de paroi sur un mélange binaire critique; (ii) adsorption de polymêres flexibles à partir d'un bon solvant.

\begin{abstract}
The reflectance of non homogeneous layers is usually calculated by numerical solution of the llaxwell equations. This requires a specific model for the layer structure. He are interested here in the inverse problem : to find the refraction index profile $n(z)$ from the ellipsometric data ( $\psi$ and $\Delta)$. We have calculated the reflectances explicitly in a lst Born approximation (i.e. to first order in $n(z)-n_{0}$ where $n_{0}$ is the index of the pure liquid). The effect of the reflecting wall at $z=0$ is incorporated exactly. Finally we express $\psi$ and $\Delta$ in terms of the complex Fourier transform $\Gamma(2 q)=\Gamma^{\prime}+i \Gamma^{\prime \prime}$ of the profile (where $q$ is the normal component of the incident wave vector). For thick diffuse layers (e >> $\lambda / 4 \pi$ ) this should allow for a complete reconstruction of the profile. For thin layers $(e<\lambda / 4 \pi)$ what is really measured is the moments $\Gamma_{0}$ and $\Gamma_{1}$ (of order 0 and 1 ) of the index profile. To illustrate these methods, we discuss two specific examples, which are associated with a slowly decreasing index profile : (i) wall effects in critical binary mixtures; (ii) polymer adsorption from a good solvent.
\end{abstract}

Reflectance measurements can give us a rather detailed information on the structure of diffuse interfaces, even when the thickness e of the interface is somewhat smaller than the optical wavelength $\lambda$ : we can probe conveniently values of $e \sim \lambda / 4 \pi \sim 500 \AA$. For oblique incidence, one can define two complex reflectance coefficients, $R_{S}$ and $R_{p}$ corresponding to the two polarisation states " $s$ " and " $p$ ". The quantity of experimental interest is the ratio: $R_{p} / R_{s} \equiv \tan \psi e^{i \Delta}$. For simple situations, such as a wall covered by a slab of thickness $e$ and constant refractive index $n_{1}$, we have relatively simple formulas for $R_{s}$ and $R_{p} / 1,2 /$. There are a number of cases, however, where this model is not satisfactory. We shall quote two examples of current interest a) a critical binary liquid mixture, near a wall, shows a profile of a concentration 
$\phi$ (versus distance to the wall, z) of the form $/ 3,4 /: \phi(z)-\phi(\infty)=($ const. $)(a / z)^{\beta / \nu}$ where $B$ and $\nu$ are critical exponents $(B / \nu \sim 0.5$ in three dimensions) and $a$ is a molecular size;

b) an adsorbed layer of flexible polymers (in a good solvent) is expected to show a concentration profile $/ 5,6 /: \phi(z)=$ const. $(a / z)^{4 / 3}$. In both cases $(a)$ and $(b), \phi(z)$ is a slowly decreasing function of $z$, and it is not at all permissible to replace the profile by a slab of finite thickness $e$ and constant index $n_{1}$ : if we did this, the apparent thickness $e$ would become a function of the experimental conditions (wavelength, angle of incidence).

Another important feature of cases $(a)$ and $(b)$ is that there is a cutt off $z_{\text {max }}$ to the profile. In case (a), $z_{\max }$ is the correlation length $\xi$ and is finite when we are not exactly at the critical point. In case (b), $z_{\max }$ is the coil size /6/. One of the questions to be clarified is the influence of this cut off on $\Delta$ and $\psi$.

This has led us to search for a general formulation where $\psi$ and $\Delta$ would be written explicitly as functionals of the profile. It is not too hard to realise this program when the Tocal perturbation $\phi(z)-\phi(\infty)$ is small. We derive the reflectance amplitudes to first order in this local perturbation, by a procedure reminiscent of the Born approximation in quantum mechanics $/ 7 /$. The problem is not entirely classical, however, because we incorporate in the 0 order wave functions the effect of the reflecting wall (at $z=0$ ).

After some calculation we can write the ellipsometric ratio to first order in $\delta$ as : $R_{p} / P_{s}=\tan \psi e^{i \Delta}=r_{p} / r_{s}(1+i A \Gamma(-2 q)+i e \Gamma(2 q))$ where :

- $r_{s}$ and $r_{p}$ are the reflectances for the wall in direct contact with a haif space of index $n_{0}$ (without diffuse layer);

- $A$ and $B$ are two known functions of $q$ and of the unperturbed reflectances :

$A(q)=a(q)\left(r_{p}^{-1}-r_{s}^{-1}\right)-b(q) r_{p}^{-1}$ with $a(q)=n_{0}(w / c)^{2} q^{-1}$

$B(q)=a(q)\left(r_{p}-r_{s}\right)-b(q) r_{p} \quad b(q)=2 n_{0}^{-1} q$

- and $\Gamma(k)$ the Fourier transform of the index profile

$r(k)=\int_{0}^{\infty} d z \operatorname{sn}(z) e^{i k z}=\Gamma^{*}(-k)$.

Our discussion of what is really measured in an ellipsometric experiment is restricted to diffuse layers where the refractive index is not too different from the bulk

value. But within these limits we can discuss arbitrary shapes for the index profile. Two limiting cases are of particular interest :

(i) thick layers where one can reconstruct the profile from the data by standard Fourier transform procedures. (Note that the Kramers Kronig relations give us some extra information);

(ii) thin layers (thickness $z_{\max }$ below $\lambda / 4 \pi$ where $\lambda$ is the optical wavelength) where one may expand $R_{p} / R_{s}$ in powers of $\left(4 \pi z_{\max } / \lambda\right)$. The data give only two informations: the first moments $\Gamma_{0}$ and $I_{1}$ of the profile. We recover here a set of relations between reflectances and moments which was first constructed by Lekner $/ 8 /$.

For this second case, it is sometimes instructive to define an apparent thickness $e_{a}$ for the layer : $e_{a}=2 r_{1} / r_{0}$. For a homoneneous slab of thickness $e$, we return to $e_{a}=e$ exactly). When we analyse the moment structure for the examples of diffuse layers:

a) for a critical binary fluid, where the profile decreases slowly like $z^{-1 / 2}$, the (0) 
moment is very dependent on the cut off $\xi$ (the correlation lentgh) $\Gamma_{0} \sim \xi^{1 / 2}$ and the apparent thickness is of order $\xi$ : in this case $e_{a}$ is a rather good image of the overall size;

b) for flexible polymer adsorption, the profile is slightly steeper $\left(z^{-4 / 3}\right)$ and this leads to very different conclusions. The $(0)$ moment is unsensitive to the cut off $R_{F}$ (the coil size), and the effective thickness $\mathrm{e}_{\mathrm{a}}$ is not proportional to $R_{F}$, but to a weaker power $e_{a} \sim R_{F}^{2 / 3}$. Thus this second example shows very vividiy the pit= falls of all models based on homogeneous slabs.

\section{References}

11/ - AZZAM R., BASHARA N.R., "ElTipsometry and polarised light", North Holland, Amsterdam (1977).

12/ - BORN li., WOLF E., "Principles of optics", Pergamon Press (1975).

13/ - FISHER M., de GENNES P.G., C.R. Acad. SCi. (Paris) B287 (1978) 207. AU-YANG H., FISHER M., Phys. Rev. B21 (1980) 3956.

AU-YANG H., FISHER M., Physica 101A (1980) 255.

14/ - FRANK C., SCHNATTERLEY S., Phys. Rev. Lett. 48 (1982) 762.

15/ - de GENNES P.G., "Scaling concepts in polymer physics", Cornell U. Press, Ithaca (NY) (1979).

16/ - de GENNES P.G., Macromolecules 14 (1981) 1637.

$17 /$ - MORSE P.M., FESHEACH H., "Methods of theoretical physics", Hic Sraw Hill, ch. 9.3 (1953).

18/ - LEKNER J., Physica 112A (1982) 544. 